\title{
Mechanism of Ursolic Acid-Mediated Inhibition of Proliferation in Vascular Endothelial Glioaytoma
}

\author{
Lin-Qi Ye ${ }^{1}$, Xiu-Feng $\mathrm{Ye}^{2}$ and Hong $\mathrm{Xu}^{3^{*}}$ \\ ${ }^{1}$ Life Science and Technology Institute of Yangtze Normal University, Chongqing, ${ }^{2}$ Department of Pathology, Chongqing Medical \\ University, Chongqing, China, ${ }^{3}$ Karolinska Institutet, Onco Reg AB, Sweden.
}

*For correspondence: Email: xuhong10@126.com; Phone/Fax: +86-23-72374466

Received: 12 June 2012

Revised accepted: 28 July 2013

\begin{abstract}
Purpose: To investigate the effects of ursolic acid (UA) on expressions of ERK1, C-Jun, C-Myc and Cyclin D1 in Human Umbilical Vein Endothelial Cells (HUVEC), and to explore the mechanism of anticancer activity of UA on glioma.

Methods: HUVEC was treated with UA $(0,31.5,62.5,125,250,500 \mu \mathrm{g} / \mathrm{mL})$ for $24 \mathrm{~h}$, and $125 \mu \mathrm{g} / \mathrm{mL}$ for $0,12,24,48 \mathrm{~h}$, respectively) and PD98059 in vitro. Real-time polymerase chain reaction (RT-PCR) was performed to measure the endogenous mRNA levels of ERK1, C-Jun, C-Myc, and Cyclin D1, and Western blotting was used to determine the expressions of ERK1, C-Jun, C-Myc, and Cyclin D1 proteins.

Results: The results show that the mRNA levels of ERK1, C-Jun, C-Myc, and Cyclin D1 were downregulated, following treatment with UA (in a dose- and time-dependent manner) and PD98059 ( $p<$ 0.05). In addition, the protein expressions of ERK1, C-Jun, C-Myc, and cyclin D1 were all significantly down-regulated, after treatment with UA (in a dose- and time-dependent manner) and PD98059 ( $p<$ 0.05).

Conclusion: The findings indicate that UA can significantly inhibit the generation of vascular endothelial cells of glioma by down-regulating the expressions of ERK1, C-Jun, C-Myc and Cyclin D1 of ERK signal transduction pathway.
\end{abstract}

Keywords: Ursolic acid, Vascular endothelial cell, ERK signal pathway, Glioma, Down-regulation, Anticancer

Tropical Journal of Pharmaceutical Research is indexed by Science Citation Index (SciSearch), Scopus, International Pharmaceutical Abstract, Chemical Abstracts, Embase, Index Copernicus, EBSCO, African Index Medicus, JournalSeek, Journal Citation Reports/Science Edition, Directory of Open Access Journals (DOAJ), African Journal Online, Bioline International, Open-J-Gate and Pharmacy Abstracts

\section{INTRODUCTION}

Ursolic acid (UA) is a pentacyclic triterpenoid isolated from Chinese herbal medicine and exists widely in Bearberry, Ligustrum lucidum. Pharmacological studies indicate that it has many biological effects [1]. Recent investigations suggest that UA not only has wide resistance to the effects of carcinogens, but also inhibits endothelial cell proliferation [2] and tumor formation [3]. It has drawn increasing interest as one of the most promising cancer chemopreventive drugs in the world; however, the mechanism of its action is still unclear. Recently, it was reported that UA functions as an anti-proliferation agent of U87 glioma cells [4].

The malignant proliferation of C6 glioma cells can be inhibited by inhibiting the activity of ERK signaling pathway [5]. Furthermore, it has also been confirmed that VEGF can promote endothelial cell mitosis by activation of ERK signaling pathway. From results of the previous investigations, we believe that UA may inhibit the proliferation of astrocyte tumor vascular endothelial cells by inhibiting ERK signaling pathway, thereby inhibiting the growth of glioma. 
In the present study, the effects of UA on ERK1, C-Jun, C-Myc, Cyclin D1 expressions in HUVEC were investigated with malignant glioma vascular endothelial cells by using RT-PCR and Western blot. The present investigation is designed to study the molecular mechanisms by which UA inhibits tumor cell proliferation, as well as develop a new biological target and new ideas in glioma biological treatment.

Table 1: Primers used for PCR

\begin{tabular}{|c|c|c|}
\hline $\begin{array}{l}\text { Gene } \\
\text { name }\end{array}$ & Primer sequence & $\begin{array}{l}\text { Length } \\
\text { (bp) }\end{array}$ \\
\hline \multirow[t]{3}{*}{ ERK1 } & $\begin{array}{l}\text { F: 5'-CTGACGGAGTATGTGGCTAC- } \\
\text { 3' }\end{array}$ & \multirow{3}{*}{255} \\
\hline & $\mathrm{R}: \quad$ 5'- & \\
\hline & $\begin{array}{l}\text { GGGCAGAGACTGTAGGTAGTTTC- } \\
\text { 3' }\end{array}$ & \\
\hline \multirow[t]{3}{*}{ C-Myc } & $\begin{array}{l}\text { F: 5'-AGGCGAACACACAACGTCTT- } \\
\text { 3' }\end{array}$ & \multirow{3}{*}{156} \\
\hline & R: $\quad$ 5'- & \\
\hline & TTGGACGGACAGGATGTATGC-3’' & \\
\hline \multirow{3}{*}{ C-Jun } & F: $\quad$ 5'- & \multirow{3}{*}{242} \\
\hline & TGGAAACGACCTTCTATGACGA-3' & \\
\hline & $\begin{array}{l}\text { R: } \\
\text { GTTGCTGGACTGGATTATCAGG-' }\end{array}$ & \\
\hline \multirow{2}{*}{$\begin{array}{l}\text { Cyclin } \\
\text { D1 }\end{array}$} & F: 5'-GTGCTGCGAAGTGGAAACC- & \multirow[b]{2}{*}{174} \\
\hline & $\begin{array}{l}\text { 3' } \\
\text { R: 5'-ATCCAGGTGGCGACGATCT- } \\
\text { 3' }\end{array}$ & \\
\hline \multirow[t]{2}{*}{$\beta$-actin } & $\begin{array}{l}\text { F: } \\
\text { AACCGCGAGAAGATGACCCAG-3' }\end{array}$ & \multirow{2}{*}{467} \\
\hline & $\begin{array}{l}\text { R: } \\
\text { CCACAGGACTCCATGCCCAG-3, }\end{array}$ & \\
\hline \multirow[t]{2}{*}{$\beta$-actin } & $\begin{array}{l}\text { F: } \\
\text { TCCTGTGGCATCCACGAAACT-3, }\end{array}$ & \\
\hline & $\begin{array}{l}\text { R: } \\
\text { GTCAAGAAAGGGTGTAACGCAAC- } \\
\text { 3' }\end{array}$ & 365 \\
\hline
\end{tabular}

\section{EXPERIMENTAL}

\section{Cell culture}

HUVEC cell lines were provided by the Department of Pathology, Chongqing Medical University, P.R. China. HUVEC were placed in RPMI1640 medium with $20 \%$ fetal calf serum and put into $37{ }^{\circ} \mathrm{C}, 5 \% \mathrm{CO}_{2}$ incubator in normal culture.

\section{Chemicals}

RPMI1640 culture medium (Hyclone, USA); Standard FBS (Hangzhou Sijiqing Biological Engineering Materials Co, Ltd, China); ursolic acid (Xu Huang Plant Science Technology Development Co., Ltd. in Shanxi, China); PD98059 (Promaga, USA); DNA Marker [Tiangen Biotech (Beijing) Co, Ltd, China]; Biozol RNA extraction kit (Bioflux, Japan); RT-PCR reaction kit (TaKaRa); PRO-PREP ${ }^{T M}$ protein extracts (SBS Genetech Co, Ltd, Beijing, China); Bradford Protein Assay Kit (Shanghai Sangon
Biological Engineering Technology \& Services Co, Ltd, China); Page Ruler TMP restained Protein Ladder (Fermentas USA); PVDF membrane (Millipore, USA); Western Blotting Luminol Reagent (Santa Cruz, USA); $\beta$-actin (C4) antibody (Santa Cruz USA); C-Myc antibody (Chemicon USA); C-Jun antibody (Santa Cruz, USA); ERK1 antibody (Santa Cruz USA); CyclinD1 antibody (Santa Cruz, USA); Horseradish peroxidase labeled goat anti-rabbit IgG (Beijing zhongshan Goldenbridge Biotechnology Co, Ltd, China); Horseradish peroxidase labeled goat anti-mouse IgG (Beijing zhongshan Goldenbridge Biotechnology Co, Ltd, China).

\section{RT-PCR examination and ERK1, C-Myc, C-Jun and Cyclin D1 mRNA expression}

Cells were harvested, and the total RNA was extracted according to BIOZOL reagent instruction manual. Total RNA was used for cDNA synthesis by reverse transcription, and cDNA of ERK1, C-Myc, C-Jun, Cyclin D1 and $\beta$ actin were amplified by PCR. All mRNA primers were designed by Primer Premier 5.0 and synthesised by SBS Genetech Co, Ltd. The primers used for the PCR are in Table 1. PCR was performed according to the manufacturer's instructions of RT-PCR reaction kit (TaKaRa, Japan). Amplification products were analyzed on $1.0 \%$ agarose gel electrophoresis and computer image analysis meter. Agarose gel electrophoresis was undertaken to analyze the PCR products and their photos collected. Electrophoresis band intensities of ERK1, C-Myc, C-Jun, CyclinD1 mRNA/ $\beta$-actin were determined by imaging analysis system and statistical analysis software and the optical density (OD) of ERK1, C-Myc,C-Jun ,Cyclin D1 mRNA/ $\beta$-actin calculated.

\section{Expressions of ERK1, C-Myc, C-Jun and CyclinD1 proteins}

Cells were harvested, and the total protein was extracted. Then, equal amounts of protein (40 $\mu \mathrm{g}$ ) were separated by sodium dodecyl sulfate/polyacrylamide gel electrophoresis (SDS/PAGE), blotted on polyvinylidene difluoride (PVDF), and probed with rabbit anti- human ERK1 or C-Myc or C-Jun or Cyclin D1 polyclonal anti-body, and subsequently with goat antirabbit/HRP, and detected by chemiluminescence. To measure protein loading, antibodies directed against $\beta$-actin were used. Comparison and analysis of area and gray intensity of electrophoresis bands were performed by the Quantity one 1D gel analysis software (version 4.6.2, Bio-Rad). 


\section{Statistical analysis}

All of the data are presented as mean $\pm S D$, and were evaluated with one-way ANOVA followed by Dunnett multiple comparisons post-test between different groups. Statistical analysis was carried out using SPSS software (SPSS for Windows, version 15.0, SPSS Inc, USA) with the level of significance set $p<0.05$.

\section{RESULTS}

\section{mRNA expression of ERK1, C-Myc,C- Jun,Cyclin D1}

The results show that expression of ERK1,CMyc,C-Jun,CyclinD1 mRNA of HUVEC in group 1(treated with $125 \mu \mathrm{g} / \mathrm{ml} \mathrm{UA}$ ) and group 2(treated with PD98059 $100 \mu \mathrm{mol} / \mathrm{L})$ were significantly lower than one of blank control group $(p<0.05)$, as Figure 1 indicates.
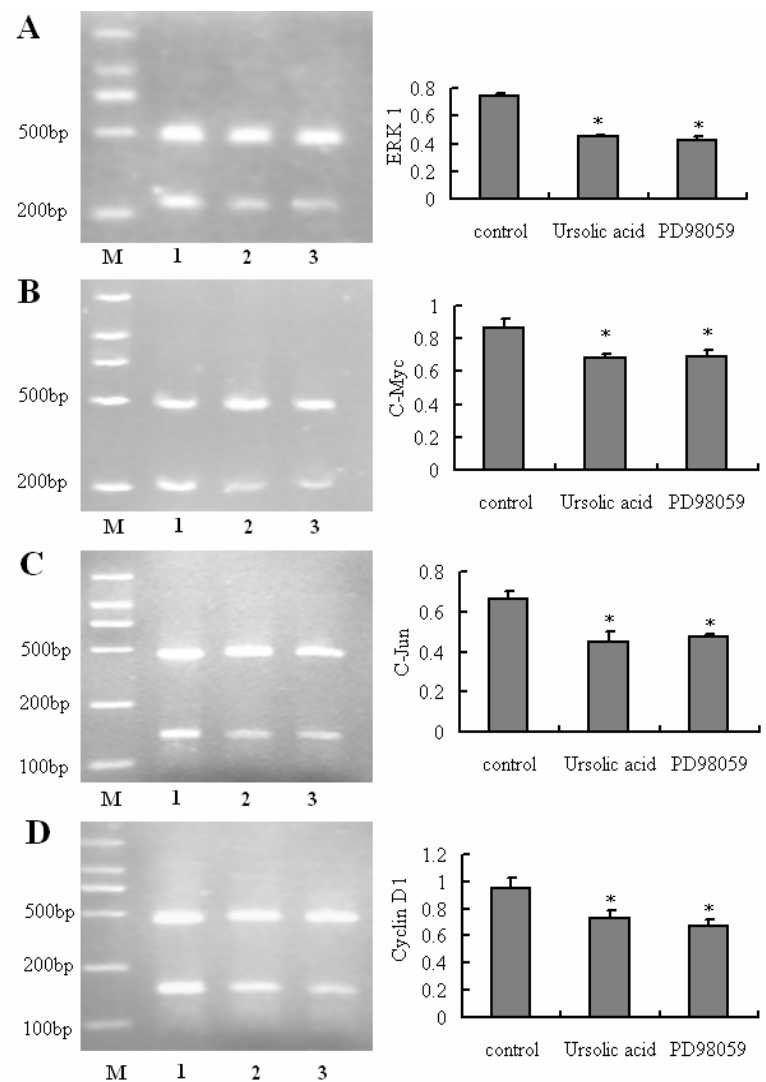

Figure 1: mRNA expressions of ERK1, c-Jun, c-Myc, Cyclin D1 in HUVEC treated with Ursolic acid and PD98059. M: Marker; 1-3 represented blank control group, Ursolic acid group and PD98059 group, respectively.

After HUVEC were treated with different UA doses $(0,31.5,62.5,125,250,500 \mu \mathrm{g} / \mathrm{mL})$, the expression of ERK1, C-Myc, C-Jun, Cyclin D1 mRNA decreased with UA dosage increase and then the expression of ERK1, C-Myc, C-Jun,
CyclinD1 mRNA were significantly different beginning from $125 \mu \mathrm{g} / \mathrm{ml}$ UA dosage between groups treated with different dosage and control group, among groups treated with different dosage. The differences were statistically significant $(p<0.05)$, as shown in Figure 2.

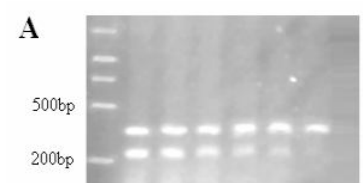

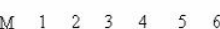
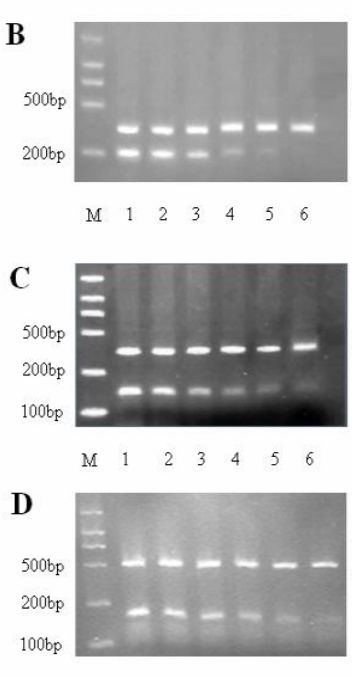

$\begin{array}{lllllll}M & 1 & 2 & 3 & 4 & 5\end{array}$
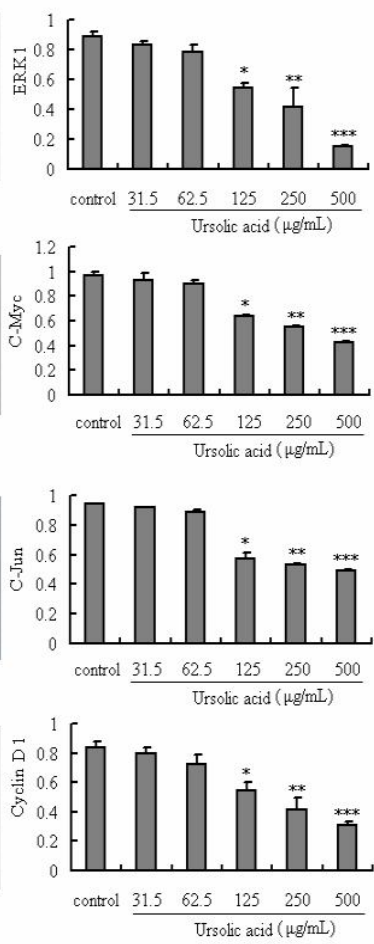

Figure 2: mRNA Expressions of ERK1, c-Jun, c-Myc, Cyclin D1 in HUVEC treated with different Ursolic acid dosage. M: Marker;1-6 represented 1.0, 31. 5, 62.5, 125,250 and $500 \mu \mathrm{g} / \mathrm{mL}$, respectively.

Further, after HUVEC were treated with $125 \mu \mathrm{g} / \mathrm{ml}$ UA dosage, the PCR results showed that the expressions of ERK1, C-Myc, C-Jun, Cyclin D1 mRNA decreased with time and then the expression of ERK1, C-Myc, C-Jun, CyclinD1 mRNA were significantly different beginning from the 12th hour between different time groups and control group, among different time groups (Figure 3 ). The differences are statistically significant $(p<0.05)$.

\section{Expressions of ERK1, C-Myc, C-Jun, and Cyclin D1}

Western blot results were obtained from image analysis (Figure 4). The results indicate that expression of ERK1, C-Myc, C-Jun, CyclinD1 of HUVEC in UA and PD98059 groups were significantly lower than that of control $(p<0.05)$.

After HUVEC were treated with different UA doses $(0,31.5,62.5,125,250$ and $500 \mu \mathrm{g} / \mathrm{mL})$, the expressions of ERK1, C-Myc, C-Jun, Cyclin D1 decreased with increase in UA (Figure 5); the 
expressions of ERK1, C-Myc, C-Jun, CyclinD1 mRNA were significantly different at UA doses of 125,250 and $500 \mu \mathrm{g} / \mathrm{mL}(p<0.05)$.
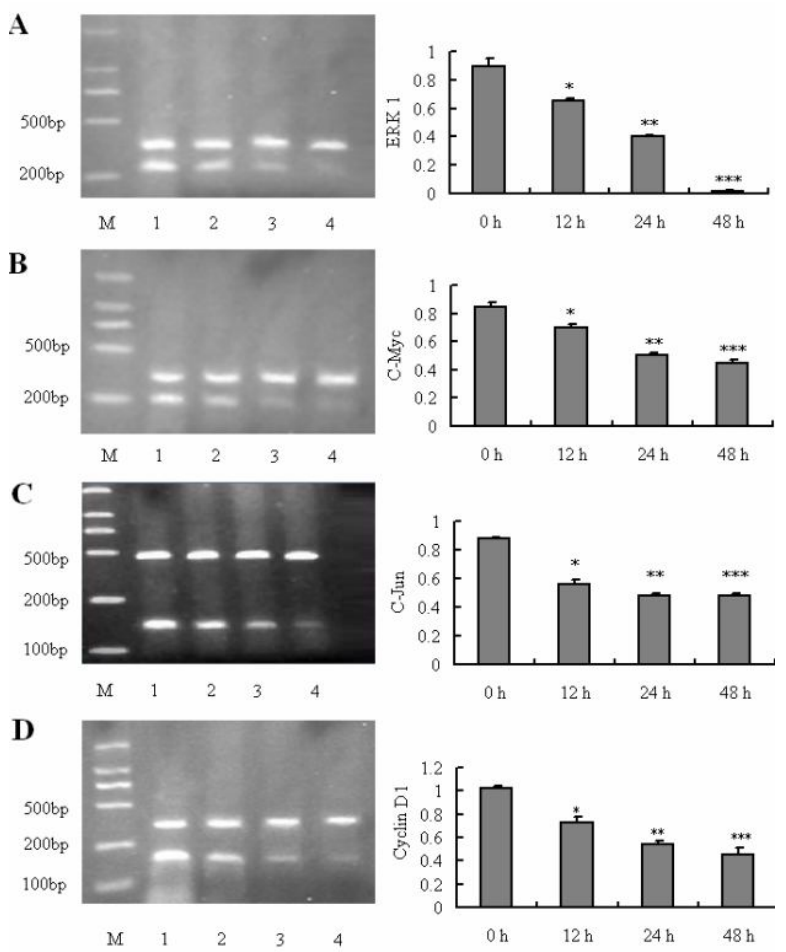

Figure 3: mRNA Expressions of ERK1, c-Jun, c-Myc, Cyclin D1 in HUVEC treated with ursolic acid at different times. M: Marker;1-4 represented 1, 12, 24 and 48 hours, respectively
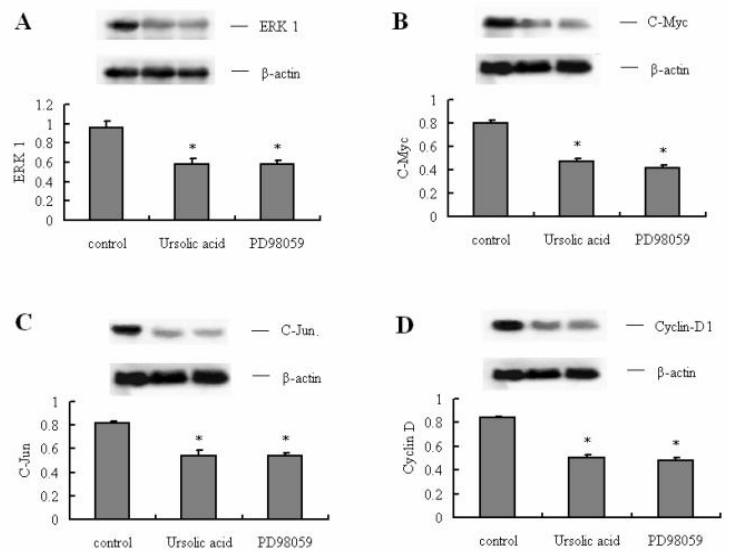

Figure 4: Expressions of ERK1, c-Jun, c-Myc, Cyclin D1 in HUVEC treated with Ursolic acid and PD98059

In addition, following treatment of HUVEC with $125 \mu \mathrm{g} / \mathrm{ml} \mathrm{UA}$, the expression of ERK1, C-Myc, C-Jun, Cyclin D1 mRNA decreased with time (Figure 6); the expression of ERK1, C-Myc,CJun,CyclinD1 were significantly different in the groups of 12, 24 and $48 \mathrm{~h}(p<0.05)$.
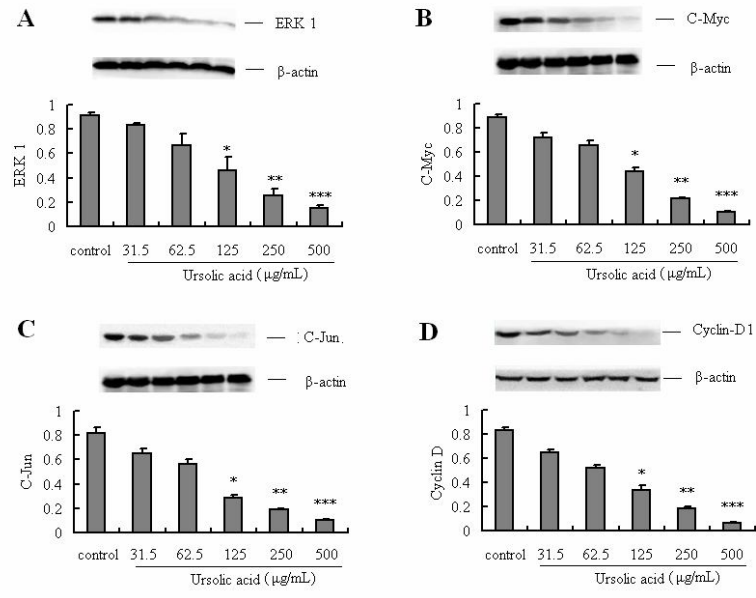
Uredic acid $(\mu \mathrm{g} / \mathrm{mI})$

Figure 5: Expressions of ERK1, c-Jun, c-Myc, Cyclin D1 in HUVEC treated with different Ursolic acid dosage
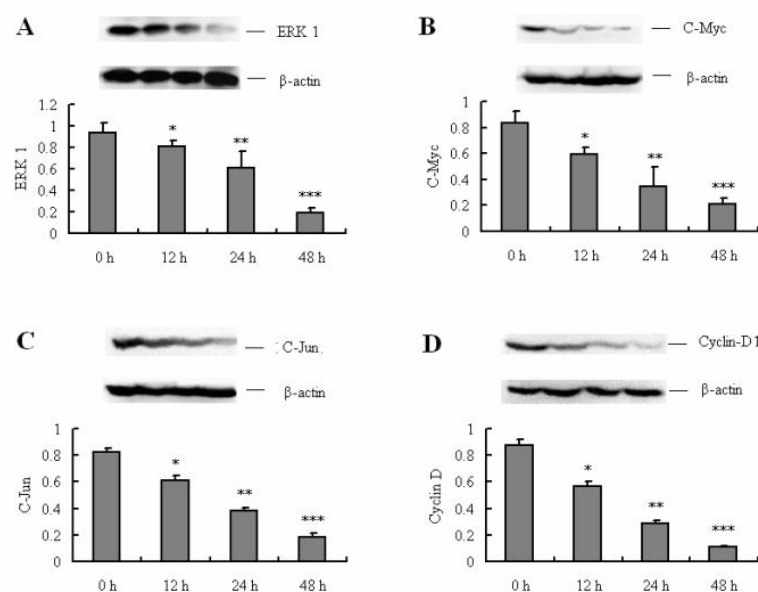

D

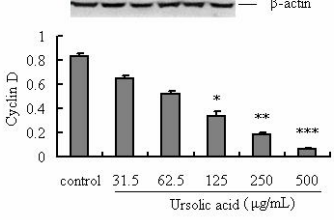

Figure 6: Expressions of ERK1, c-Jun, c-Myc, Cyclin D1 in HUVEC treated with ursolic acid at different times

\section{DISCUSSION}

Chinese herbal medicines have been used in China for treatment of a wide variety of diseases with low adverse effects [6, 7]. UA is an $\alpha-$ amyrin-type pentacyclic triterpenoid, and has wide biology effects, including inhibition of growth of various malignant cells [1]. Currently, its anticancer effect is attracting considerable attention from pharmacologists. Angiogenesis is the key pathological process of tumor development and metastasis [8]. In tumor angiogenesis, activation, proliferation, migration and canaliculization of vascular endothelia cells (VEC) are important steps. Now many angiogenesis inhibitors, such as trotamine, interferon and platelet factor IV have been found but their clinical applications have been restricted because of high toxicity. As a potent new anti-tumor natural drug with high 
anti-tumor effect and low toxicity, UA has vast potential as a new drug for cancer treatment [9].

Wang et al [10] suggested that UA has the ability to inhibit angiopoiesis of proliferative phase VEC in-vitro in a dose-dependent manner. Sohn et al [11] also obtained similar results using chorioallantoic membranes (CAM) of chicken embryo model. However, the mechanism of UA action is not yet clear. In our present study, we focused on the mechanism of inhibition of VEC proliferation by UA. PD98059 is a powerful ERK inhibitor which can selectively inhibit ERK activity so as to inhibit the proliferation of malignant glioma cells C6, thereby inducing their differentiation. The RT-PCR results of our present study show that expressions of ERK1, CMyc, C-Jun, CyclinD1 mRNA of HUVEC in UA group and PD98059 group were significantly lower than that of blank control group $(p<0.05)$ This indicates that both UA and PD98059 can inhibit the ERK signal pathway of HUVEC. Western blot results revealed that expressions of ERK1, C-Myc, C-Jun, CyclinD1 of HUVEC in UA group and PD98059 group were significantly lower than that of blank control group $(p<0.05)$, and the results further demonstrate that UA can inhibit the ERK signal pathway of HUVEC, just like PD98059 effect, which is consistent with some literature reports 12,13]. Huang et al [14] suggested that the inhibition of ERK1/2 signal pathway may block VEC proliferation in their research on effects of tumstatin peptide on retinal microvascular endothelial cell (RMEC) proliferation. Therefore, we presume that UA and PD98059 can inhibit VEC proliferation by inhibiting the ERK signal pathway of HUVEC. Our results also show that the expressions of ERK1, C-Myc, C-Jun, Cyclin D1 mRNA and protein decreased gradually with UA dose and time and were significantly different between different dosage and time groups $(p<0.05)$. This shows that the inhibition of the ERK signal pathway of HUVEC by UA is dose- and timedependent.

\section{CONCLUSION}

The findings of the present study indicate that the UA can significantly inhibit the generation of vascular endothelial cells of glioma by downregulating the expressions of ERK1, C-Jun, CMyc and Cyclin D1 of ERK signal transduction pathway, which is of potential value for the treatment of vascular endothelial glioaytoma.

\section{ACKNOWLEDGEMENT}

This project was supported by Chunhui Project (no. Z2009-9-1-63007) of Ministry of Education of China.

\section{REFERENCES}

1. Machado DG, Neis VB, Balen GO, Colla A, Cunha MP, Dalmarco JB, Pizzolatti MG, Prediger RD, Rodrigues ALS. Antidepressant-like effect of ursolic acid isolated from Rosmarinus officinalis $L$. in mice: Evdence for the involvement of the dopaminergic system. Pharmacol Biochem Behav 2012; 103: 204-211.

2. Bikul D, Herman Y, Rika T. A hypoxia-driven vascular endothelial growth factor/Flt1 autocrine loop interacts with hypoxia-inducible factor-1a through mitogen-activated protein kinase/extracellular signal-regulated kinase $1 / 2$ pathway in neuroblastoma. Cancer Res 2005; 65: 7267-7275.

3. Wang T, Song HY, Zhao DM. Experimental study for Fuan-te injection on transplantable carcinomas in mice. Chin J Vet Med 2007; 43: 28-29.

4. Bonaccorsi I, Altieri F, Sciamanna I. Endogenons reverse transcriptase as a mediator of ursolic acid's anti-proliferative and differentiating effects in human cancer cell lines. Cancer Lett 2008; 263: 130-139.

5. Mijatovic S, Maksimovic-Ivanic D, Radovic J. Anti-glioma action of aloe emodin: the role of ERK inhibition. Cell Mol Life Sci 2005; 62: 589-598.

6. Peng W, Guo L, Zheng CJ, Zhang QY, Zhang $H$, Huang BK. Two new azaphilone alkaloids dimers from endophytic Chaetomium fusiform of the liverwort Scapania verrucosa Heeg. Biochem Syst Ecol 2012; 45: 124-126.

7. Rarnsewak RS, DeWitt DL, Nair MG. Cytotoxicity, antioxidant and anti-inflammatory activities of Curcumins I-III from Curcuma longa. Phytomed 2000; 7: 303-308.

8. Folkman J. Role of angiogenesis in tumor growth and metastasis. Semin Oncol 2002; 29: 15-18.

9. Garcia-Vilas JA, Quesada AR, Medina MA. 4Methylumbelliferone inhibits angiogensis in vitro and in vivo. J Agric Food Chem 2013, DOI: $10.1021 / \mathrm{jf303062h}$.

10. Wang JJ, Wang B, Guo J. Inhibitory effect of ursolic acid on angiogenesis in vitro. Acad $\mathrm{J}$ Sec Mili Med Uni 2000, 21: 1071-I073.

11. Sohn $\mathrm{KH}$, Lee $H Y$, Chung $H Y$. Anti-angiogenesis activity of triterpene acids. Cancer Lett 1995; 94: 213-217.

12. Hao YW, Zhou WL, Liu XZ. Mechanism of protein kinase $C$ regulating $C D 44$ gene expression in vascular endothelial cells. Chin J Immunol 2007; 23:975-978

13. Yuan HS, Wang $P$. Efects of ursolic acid on the proliferation of glioma cell line U25I. Herald of Med 2008; 27: 1440-1442.

Huang ML, Luo GR, Chen WP. The effect of tumstatin peptide on the proliferation and expression of extracellular signal regulated protein kinase in retinal microvascular endothelial cells. Guangdong Medl J 2007; 29: 1955-1958. 